\title{
English Language Teaching and Whole School Professional Development in Tanzania
}

\author{
Abstract \\ This paper reports a two-year in-depth qualitative enquiry into English language \\ teaching in a typical primary school in an economically deprived ward of Dar es Salaam, \\ Tanzania. The research found that modest but significant changes to teachers' \\ pedagogy, practice and understanding of the teaching of English could be achieved. \\ One of the most important changes was the teachers' increased understanding of the \\ benefits of engaging learners in a greater range of interaction styles. Another important \\ change was greater understanding of the importance of communicative intent and \\ semantics in the teaching of English. The whole school approach to teacher \\ development, including the research team's sustained engagement with the head \\ teacher of the school, was an important context for the changes to practice.
}

Key words: Teaching English; capacity building; Tanzania; primary school; pedagogy.

\subsection{Introduction}

Global commitment to the Millennium Development Goals (MDG) has increased access to primary education for millions of children around the world especially in Sub-Saharan Africa. In the Republic of Tanzania significant strides have been made and the net enrolment ratio in primary school doubled from 54\% in 2000 to $95.9 \%$ in 2010 (United Nations, 2010). Although this is a sign of clear improvement there are severe challenges facing schools and teachers in Tanzania, such as overcrowded classrooms, lack of resources, poor training, and low qualifications. Another key issue is the quality of education once pupils are in school. As part of thinking about quality there has been a growing interest in reforming teacher education particularly in teacher training colleges (Hardman et al. 2012; Vavrus, 2013) but little research has looked at how to improve teaching and learning in the context of schools.

The context for research in Tanzania, as part of the wider development education field, includes work on the historical, political, cultural and economic implications of language of instruction. As part of colonial rule the British promoted the use of English as the medium of instruction in primary, secondary and tertiary education in Tanzania, and as an official language (Brock-Utne and Holmarsdottir, 2004). Shortly after independence in 1961 Kiswahili became the national language of the country. The rationale behind this decision was to unify Tanzanians with one 'national' language. This resulted in a deliberate political decision to use Kiswahili as the official language of the government (Barrett, 1994). Although Kiswahili became the medium of instruction in primary schools in 1967, the language of instruction in secondary schools remained as English. Debate has continued about language policy (or the lack of) in Tanzania (Brock-Utne and 
Holmarsdottir, 2004). Some advocate that Kiswahili should be the only medium of instruction throughout the educational system because it is claimed that English is not used outside the classroom, and hence it is recommended that the Tanzanian government revisit their language policy for education (Brock-Utne et al, 2003; Rubagamya, 1997). However, others such as Kadeghe (2010) fear that Tanzania is missing out on global opportunities because of poor grasp of English.

Although a considerable amount of empirical work focusing on the language of instruction has been carried out, including some in Tanzania, research on the teaching of English in Tanzania is scarce. Evidence of the challenges for pupils learning English has been established by a significant study carried out by a non-governmental organisation which found large numbers of pupils struggling to acquire the English knowledge and understanding necessary for secondary education (Uwezo and Sumara, 2010). In a broader study of interaction across all the subjects of the primary curriculum, including English, O-Saki and Agu (2002) found that teacher interaction styles were orthodox, typically consisting of teacher expositions and the requirement for pupils to answer questions requiring factual recall.

Lewin and Stuart's study of teacher education in Ghana, Lesotho, Malawi, South Africa and Trinidad and Tobago found that newly qualified teachers valued their initial teacher training, and had benefited from new knowledge, new skills and resource materials. But there did not appear to be much impact on the teachers' "behaviour, attitudes or understandings" (Lewin \& Stuart, 2003, p. 701). The demands of limited resources were also part of the context for a study of secondary education in Tanzania (Vavrus and Bartlett, 2013). Tensions between constructivist theories of knowledge and cultural values related to teachers' authority in the community were also evident (Bartlett and Mogusu, 2013). Hardman et al. (2012) found that most schools in their sample of schools in Tanzania were not equipped with the resources required to support teacher education but suggested that with the appropriate support school-based training was possible and could bring about more effective teaching and learning.

It was in the context of limited research on the pedagogy of English teaching in Tanzania, and the need for empirical evidence about the ways in which teachers' pedagogy could be developed, that a two-year research study was carried out in an urban 'resource poor' primary school in Tanzania from 2009-2011. The research examined the teaching of English from a whole school perspective, with attendant implications for school leadership and capacity building. The paper begins with a section outlining the theoretical framing that was an important feature of our overall approach to both the research and the capacity building with the school. This is followed by a report of the research findings that focuses particularly on capacity building and the teaching of English, including of English grammar. Finally the discussion and conclusions highlight the significance of changes to teacher's practice that occurred and the implications of this for sustainable professional development. 


\subsection{Theoretical Framing: Professional development and the teaching of English}

\subsection{Professional development and leadership}

Notwithstanding the challenges of sustainable educational improvement some remain optimistic that "globalisation has the potential to bring enormous benefits to those in both the developing and the developed world" (Stiglitz, 2006, p. 4). Such perspectives emphasise the 'knowledge economy' as a means of developing 'human capital' leading to work, economic activity and wealth generation. However, even in Western economies, education systems have been described as more akin to "the factory and the monastery" rather than places to prepare young people for the postmodern, postindustrial world (Hargreaves, 2003, p. 12). Thus, what is called for is a highly educated workforce that is flexible, adaptable, creative and innovative. Western perspectives on teacher professional development have shown that teachers are one of the most significant factors in the quality of learning in schools (Day et al., 2007). Teachers' "wellbeing and positive professional identity are fundamental to their capacities to become and remain effective" (op cit., pp. 236-237). While it is clear that some education systems fare much better than others in the major challenges of teacher professional development (see for example, Sahlberg, 2011), it is not surprising that initial teacher education in particular (Darling-Hammond \& Lieberman, 2012) and continuing professional development (CPD) have come under sustained attention in recent research and policy (Day, 2012). Despite the attention to teacher development, and after decades of school effectiveness and school improvement research, CPD is often characterised in the following terms:

It is brief and rarely sustained, deficit oriented, radically under-resourced, politically imposed rather than professionally owned, lacking in intellectual rigour or coherence, treated as an add-on rather than as part of a natural process and trapped in the constraints of a bureaucratic system that poses barriers to even modest levels of success. (Guskey, 2004, p. xii)

Such commentary was a cautionary tale in the context of the research being reported on in this paper, where members who were from the Faculty of Education, University of Cambridge, collaborated with a school in Dar es Salaam. We were mindful of, and sensitive to, local culture and context while seeking to avoid many of the pitfalls inherent in arriving with ready-made solutions to problems we might be impatient to solve before adequately understanding their genealogy. We took seriously the distinction between 'planners' and 'seekers' while being committed to 'professional capacity building' (Hargreaves \& Fullan, 2012). We were keen to eschew planning in favour of seeking to build capacity from the ground up.

Even if our ambition to improve teachers' capacity to teach English in one primary school was perhaps small in scale, it was nevertheless tempered by the team's previous experience working in low-income countries and knowledge of failed initiatives that promised more than they delivered. Awareness that "anytime you hear a Western 
politician or activist say 'we', they mean 'we whites' - today's version of the White Man's Burden," tempered our disposition further (Easterly, 2006, p. 23). Thus, taking time to build relationships of trust and mutual respect were important building bricks in our approach to building professional capacity on a whole school basis. We felt that by working collaboratively from the ground up we were more likely to create a sustainable legacy. Though we arrived with claims to expertise, for example in development education, leadership, and English teaching pedagogy, our disposition also included a commitment to building on elements of the teachers' existing pedagogy that were 'promising' and lent themselves to further development rather than adopt a deficit perspective.

Awareness of, and sensitivity to, traditions of school leadership in the setting were regarded by us as an important element of leading capacity building at the same time as building leadership density within the school community in a more 'distributed leadership' manner (Harris, 2008; Leithwood, Mascall, \& Strauss, 2009; Spillane \& Diamond, 2007). We were mindful that leadership is a cultural construct with considerable variation. Nevertheless, cognisance was taken of the potential of 'communities of practice' (Wenger, 1998) to cultivate, develop and sustain professional capacity, and the possibility that, together and over time, pedagogical and leadership capacity could be improved in a symbiotic manner.

Closely connected with such understandings, particularly with reference to leadership was a recognition of Ubuntu having real local meaning, i.e. that "one's humanity can ... only be defined through interaction with others" (Boon, 2007, p. 26). While we acknowledge the critique that Boon may be essentializing leadership in African contexts we reasoned it would be important to engage with the school's existing leadership as a means of building community capacity and leadership capacity through participation. Such a collective, communal commitment held out significant promise that might prove to be fertile ground for a sense of distributed leadership though how that concept might be understood locally could be significantly different from recent iterations in Western contexts where individualism and consumerism are much more culturally embedded (Harris, 2008; Leithwood, et al., 2009; Spillane \& Diamond, 2007).

Though the focus was primarily on the pedagogy of English language learning, we were conscious, from a whole-school perspective, that the leadership of organisational change could not be ignored if improvements were to be fashioned, sustained and documented. From the outset, therefore, we did not lose sight of the symbiosis between pedagogy and leadership, and sought to keep both in productive tension, something that was largely done through formal and informal dialogue between the research team, the school head teacher and key teaching personnel, while mindful at all times of retaining a whole-school dimension. Another productive tension present throughout was that between providing support through professional-development workshops and the conduct of research. 


\subsection{English language and literacy teaching}

Epistemologically our theorisation of English language and literacy teaching was multidisciplinary drawing on socio-cultural and psycholinguistic orientations. For example we recognised the value of Street's (2003) conception of the "ideological model" of literacy that sees literacy as a social practice and a phenomenon that is "rooted in conceptions of knowledge, identity and being" (op. cit. p.78). At the same time psycholinguistic understanding of literacy processes helped us to understand the importance of linguistic features across languages and more prosaically defining reading as "the process of understanding speech written down. The goal is to gain access to meaning"(Ziegler and Goswami, 2005, p.3). Aligned with such a definition was our view of the fundamental place of semantics and communicative intent in relation to language and English teaching pedagogy. The centrality of meaning was a constant referent when thinking about teachers' practice. Reading, writing, language and literacy were considered holistically, in part by virtue of teachers' role in supporting these modes within the wider curriculum, and learners' holistic experiences and conceptions. Oral language was seen as foundational to literacy including through the 'dialogic turn' in education that increasingly sheds light on the features of productive teacher-pupil interaction (Mercer, 2005). While recognising the important evidence on dialogic teaching, including in low-income country contexts (Hardman, 2010), we also theorised that the pragmatic context (in a linguistic sense) provides powerful drivers that influence social interaction. In the classroom context these forms of social interaction have to be taken into account, and the positive contribution they might make to learning in addition to the possibilities for an extended range of interaction and teaching practice.

The professional development work that the project team carried out with the teachers involved the teachers and researchers reflecting on their English teaching practice. These reflections included attention to both the broader aspects of pedagogy and whole school development, but also attention to linguistic knowledge necessary for English teaching. Linguistic understandings from existing theory and research were synthesised as a series of principles underpinning the work (a longer account addressing the origins of the theoretical influences including the linguistic principles can be found in Author, 2012): 1 . communication of understandable meaning is the driving force of language; 2. analysis of language in use is the basis for appropriate knowledge for pupils and teachers; 3 . as a consequence of the natural processes of language change descriptive accounts of language are more appropriate than prescriptive accounts; 4 . experiencing and reflecting on the processes of reading and writing are an important resource to enhance teaching and learning; 5. language and social status (or power) are inextricably linked. The centrality of meaning, aligned with an emphasis on semantics, included the understanding of metalinguistic features as labels for language rather than principle means to enhance language and literacy learning, a position consistent with the idea of descriptive rather than prescriptive grammarianism. In summary our theoretical framing privileged the holistic over the partial, the social vs. instrumental, the complex vs. the simple, the nuanced vs. the crudely straightforward. It recognised the 
socio-cultural context in which teaching is located and focused on the pedagogical aspects of the socio-cultural context.

From a research and intervention perspective we considered our theoretical framing of capacity building and language and literacy as integral, thus a holistic approach to language and literacy was complemented by a school-wide, school community approach to pedagogical improvement and capacity building. This included our view that every member of the community, beginning with the school principal, had a role to play and a responsibility to contribute through participation.

\subsection{Methodology}

The research design was an in-depth two-year qualitative enquiry into teachers' professional development and capacity building focused on improving the teaching of English and effecting organisational change. The research methodology utilised a single case design with a critical and representative case rationale (Yin, 2009). The research questions were as follows:

1. What are the dominant pedagogical patterns of teaching in English lessons throughout the school from standards one to seven?

2. What are teachers' reflections, individual and collective, on these dominant teaching patterns?

3. What are the most effective means of supporting teachers' critique of such teaching patterns with the intention to improve?

4. What can school leadership do with limited resources to improve the quality of teaching, learning and leading?

In relation to the research questions the focus of this paper is mainly on teaching and teacher development. Leadership is revealed as an important contextual framing for the work but is somewhat less of a focus because the larger data sets addressed pedagogy. In addition, although pupil learning forms part of the analysis, for example, interaction during observed lessons, the focus of the paper is more on teaching than learning.

\subsection{Context, Sites and Participants}

The formal education system on the Tanzanian mainland is based on seven years of primary school. Official entry to school is when the child is age seven. Primary schooling is organised into classes of standards from standard one to seven. This is followed by four years of lower secondary school, two years of senior secondary school, and three years of tertiary education. If a child enrols at the government prescribed age of seven, and if they progress without repetition, they should be age 13-14 years in standard seven. The transition from primary school to secondary school depends on the 
performance in the Primary School Leaving Examination, an examination that includes the subject of English.

Although generalisation on the basis of statistical significance was not a requirement for the study great care was taken to select a primary school where its socioeconomic context would be typical of urban schools in Tanzania. As a result of discussions with an educational expert at the University of Dar-es-Salaam and with District and Ward Education Officers a school in Manzese Ward in Kinondoni District in Dar-es-Salaam that was typical of economically deprived areas in the city was selected. Access to the school for the research was only possible as a result of establishing supportive partnerships with the national government Ministry, the local district and the ward. The school is located about $8 \mathrm{~km}$ from the centre of Dar es Salaam. The area is highly populated with over 5,000 households, with an estimated population of approximately 67,000 people (32,613 females; 34,389 males). The ward is divided into six sub-wards which are administrative units within the ward. Manzese is described as an 'informal settlement' where there has been very little planning in relation to building regulations, sanitation and infrastructure (Ramadhani, 2007).

On initial contact with the case study school it had a total enrolment of 1785 pupils (904 males; 881 females) with forty-three teachers (36 female; 7 male). Registration data showed that a high proportion of children transferred to and from the school which is consistent with peripatetic life in an urban environment. In 2010 the school records indicated the following primary school leaving examination scores averaged across all subjects: 1 to 50 marks $=8.33 \%$ pupils; $51-99=24.16 \% ; 100-150=38.01 \% ; 151-200=$ $25.70 \% ; 201-250=1.54 \%$. In subsequent years the government published national statistics that indicated the following in 2011: number of students passed $A$ to $C=53$; average total marks per pupil out of $250=185.84$. 40 teachers had completed the traditional teaching certificate (also known as 'Grade A' teachers) which is a two year full time course of study, two teachers had diplomas (two years duration), and one teacher had a degree (three to four years duration). All primary teachers in the school had a responsibility to support the development of pupils' English language proficiency. Some of the teachers in standards five to seven were designated as subject specialists, including some for English teaching, however a teacher's designation could change according to the school's need each year and the balance of different subject expertise amongst the teachers. Teachers in standards one to three also had responsibility to support the teaching of English but typically did not regard themselves as specialists. Each standard had three classes, with each class typically exceeding 50 pupils.

\subsection{Data collection and analysis}

Ten field visits were made during the two years of the research project, including three professional development workshops and four technical support visits, led by members of the research team (see table 1 for sequence of activities). Two members of the research team led the workshops: [author] had expertise in teacher development and 
leadership, [author] had experience in teacher development and the teaching of English. [Author] took responsibility for research data generated from the workshops. The professional development workshops usually consisted of two to three days of training which involved all teachers in the school. Prior to the commencement of the first professional development workshop seven hours of English teaching were videorecorded by members of the research team in one class from each standard (see table 2).

The data sets for the research were video recordings of English lessons, audio and video recordings of professional development workshops, interviews with teachers, and field notes recording participant observation in workshops, and more general aspects of the school and district. During the second year of study a second set of videos was made to aid reflection on developments in teaching, to identify evidence of pedagogical development, and to gather further data in order to reach theoretical saturation in our analysis.

Insert tables 1 and 2 near here

In the first workshop, videos were viewed by small groups of teachers who taught the same standard, with one of the research team as facilitator to animate and record the unfolding professional dialogue. The aims of the activity were to promote discussion of aspects of teaching, as well as creating a climate and context whereby practice became the focus of constructive and reflective dialogue, and to support and encourage all participants in their use of English. We also aimed to encourage the development of an appropriate language with which to discuss pedagogy, as well as moving beyond the 'privatism' (Lortie, 1975) of the classroom towards a more collaborative culture and a 'community of practice' (Wenger, 1998).

The methodological approach in general, and to data analysis in particular, was informed by grounded theory using constant comparative analysis. The research sought to generate theory systematically derived from the social context of the research. It was recognised that although ultimately the theory generated in the research was systematically established as a result of the acquisition and analysis of new data the sources of ideas were also initially stimulated by our understanding of socio-linguistic theories, as well as experience of providing CPD and researching its impact on leadership and organisational change. This approach to apriori and new theory was consistent with the original tenets of grounded theory (Glazer and Strauss, 1967).

Data analysis was supported by HyperRESEARCH qualitative data analysis software. Following the first round of open coding, video clips of lesson observation and audio clips of professional development workshops that reflected emerging themes were selected and coded. After open coding the criteria for selecting codes for a subsequent phase of analysis (cross-code analysis) included, a) codes with the highest frequency of codings, and b) codes that included instances across all data sets to enable 
triangulation by data (Denzin, 1970). As a result of the cross-code analysis four themes were developed: leadership and the curriculum; physical resource; teacher knowledge and pedagogy; and language use (see Table 3).

Insert Table 3 near here

Ethical approval was obtained following the ethical protocol in Tanzania and conformed to the British Educational Research Association guidelines. Consent was provided by the Research Division in the Ministry of Education and a research permit was issued based on our research proposal. Meetings were held with the ward education officer who liaised with the community about the research. The school committee sanctioned the research and parents/guardians were kept informed of the research over the two year duration. The school principal also approved the research in her school and sanctioned the use of video, photography and observation.

\subsection{Findings}

The physical conditions of all classrooms observed were similar throughout the school from standard one to standard seven. The walls of the classrooms were bare, with only very occasional use of posters or wall charts. Walls were punctuated by windows without glass. An electricity supply was not present in most classrooms. In the first few standards there were not enough chairs or desks so some children were obliged to sit on the floor.

The main teaching resources were blackboardi and chalk. Teachers also relied on textbooks produced commercially by western publishers approved by the Tanzanian education ministry. One or two textbooks were shared amongst eight or nine pupils across the standards, and in many lessons the textbooks were not given to the pupils for the entire lesson. Overall, pupils were attentive and the classes were well managed by the teachers. Lessons that were observed by the researchers often began with all pupils singing a song together and clapping hands followed by a teacher's greeting. Then the teachers gave a short introduction to the topic of the lesson, and wrote the contents of the lesson and/or questions on the blackboard for the pupils to copy. Teacher explanation and questions followed with pupils answering and repeating answers in chorus. The main lesson task would often require copying what was written on the blackboard. The lessons finished with teachers walking around the class to check pupil's writing in their workbooks. It was very rare for teachers to review the previous lesson or conclude with a summary of the lesson. In many classes, pupils spent a great amount of time on listening to the teacher's explanations, answering their questions with single word or short phrase answers, and repeating the same sentences many times. 
The extreme lack of physical resources compared to high-income countries was clearly evident but also was repeatedly mentioned by the teachers as an obstacle to better teaching. Our reflections on the conditions, our empathy with the teachers' views, but also our belief that improvement was possible in spite of the resources began a strand of thinking that informed the whole project.

\subsection{Sustainable professional capacity building}

The initial video material and the subsequent workshop revealed that there was significant variation across the staff regarding confidence and competence in the use of English. One indicator of this was the extensive need for translation from English to Kiswahili during the workshops, however the need for translation showed significant decrease during the life of the project as a result of the teachers' commitment to improving their English. There was evident realisation that, if pedagogy was to be improved, and disposition towards the teaching of English enhanced, then the use of English was an issue that would have to be addressed.

The teachers welcomed the team's initiative to provide reading material for them in the form of magazines, books, and even children's texts. In addition, as a result of the research team's encouragement during workshops for participants to envisage practical beneficial changes that might positively impact on pupils' learning, the teachers organised a school book club whereby they read and discussed selected texts on a weekly basis. Under the active encouragement of the head teacher, with the assistance of some of the more capable English teachers, such beginnings extended to community involvement. Informal use of English when interacting with the learners during the school day, and within the classroom was also encouraged for the first time. On one day per week, a policy of 'no English, no Service' was implemented, in addition a book club, and 'morning speech' for learners added to the range of initiatives. Throughout this collective endeavour, the basic commitment being required of all was that improving the quality of teaching and learning in English was the responsibility of everybody in the school community.

The combination of the head teacher's and teachers' initiative, and our support, also led to enhancements to the school learning environment. For example the hiring of a local artist to complete several murals in the school required discussions about what stimuli they would find most appropriate for the teaching of English. Thus for example, a mural depicting a map of the continent of Africa was provided with bi-lingual labels for countries. From a researcher perspective, this particular initiative also enhanced our rapport and enabled us to build trust with principal and teachers, while the collective impact of these various initiatives built the confidence and competence of teachers thus equipping them more appropriately to address the more embedded routines of practice. 
Closely associated with this organic ecological orchestration of capacity building was the 'soft power' of leadership (Nye, 2008), beginning with the head teacher. The role of the head teacher was vital to the project. In the first instance, following approval at governmental and regional level, she gave access to the school. In the early stages of the project the head teacher showed some natural cautiousness in relation to what the project might entail. It was also noticeable that the head teacher's use of the English language was quite limited at the beginning. One of the important facets of the relationship that emerged between the research team and the head teacher was the parallel developments that were seen in the head teacher's engagement with the project, and the development of her own use of English. Towards the end of the project this resulted in her confidence to create a PowerPoint presentation with one of her senior colleagues that outlined the benefits to the school that she and her teachers felt had resulted from the project.

Less visible, but ever present, was the head teacher's commitment to bringing about tangible improvements in 'her' school, and this 'sponsorship' on her part supported by the research team signalled clearly to colleagues that being part of the effort was desirable. The head teacher was supportive throughout of the work the research team did with the school, and she was present, and an active contributor, at nearly all of the workshops. Her continued presence, collaborative approach, and capacity to encourage her staff to learn were an important feature of the research.

The links in the chain of capacity building extended also to embrace the school and its community. The head teacher persuaded the school committee (similar to school governors in other countries) to support the initiative in a variety of ways. Most tangible was the purchase of a printer and Internet access after we had provided the school with a PC. Modest inputs on our part, such as provision of children's books from England, and limited materials to aid teachers' development of resources such as posters and word cards, were 'matched' by school and community commitment in a variety of ways, thus contributing to ownership and sustainability.

The physical resources came to be seen by the research team as a form of mediation (Vygotsky, 1978) that supported a focus on pedagogy, as the two following vignettes from the workshop illustrate.

\subsection{Vignette one: struggling to find a linguistic and pedagogical voice}

A minority of teachers, typically allocated to standards five, six, and seven, had relatively high levels of knowledge of English, but the majority of the teachers in the school did not, yet they all had responsibility to support the pupils' development of English. In the example below from a workshop early in the project a pair of teachers from standard two (pupils age eight to nine) were presenting a picture book to the whole workshop group. 
Two teachers are standing in front of their colleagues and the researchers during the workshop. Mr Shabani was holding a book and Ms Kamba was standing next to him.

Mr Shabani: The title of the book is, "Would you rather ...", um. Hesitation and pause.

Other teachers: Just go ... Mr Shabani didn't seem to understand. Still no response.

Other teachers: Just go ... continue! Continue! In chorus.

Mr Shabani: Oh ... in other meaning, you can say 'which do you prefer'... The writer is John Burningham, written in Singapore ... umm ... character of this book, character of this book is animal ... people ... climate andie ... so content of this book, content of this book is goodie ... and badie animal ...

Mr Shabani was struggling to continue the presentation.

Mr Shabani: At the end of presentation ... Because I'm not goodie at English. Because ... I would like to ... some ... all part of this book ... because I'm not at goodie at Englishie ... I can say ... call it a day ...

Ms Kamba: This book is for class 2.

Even in a supportive learning environment with the positive encouragement of colleagues, and the benefit of preparation for the presentation, the manifest 'reality' for these teachers was a struggle to find a professional voice that would be the basis of pedagogical improvement. However it was felt that becoming a 'learning community' (Wenger, 1998) held some promise for these and other colleagues.

\subsection{Vignette two: giving 'voice' to the pedagogical potential of active learning}

Mr Nkinga and Ms Said from standard seven and five were more confident and more fluent than their colleagues illustrated in vignette one. They attempted to simulate the model lesson by encouraging their colleagues to be involved actively in the interaction, for example by encouragement to make a full sentence. The confidence to do this came in part as a result of earlier workshop opportunities to reflect on their teaching shown in videos. For example, the use of classroom resources as a stimulus for active learning through more sophisticated questioning, and variation in teacher-pupil interaction beyond whole-class choral recital and 'one word' answers had been discussed.

During the workshop two posters made by Mr Nkinga and Ms Saidi had been stuck on the blackboard, one of which contained some pictures cut and pasted from Magazines.

Mr Nkinga: I want you to answer to the questions, which we're going to ask you. Madam teacher is going to ask you the number one question.

Ms Saidi: What do you see in picture 3?

Mr Nkinga: What do you see from the picture 3?

Colleague A: I see a watch. 
Mr Nkinga: You see a watch. Say, that is the watch? Say it again.

Colleague A: That is a watch.

Mr Nkinga: Very good! Then, is he corrected? Asking other colleagues

Whole group: Yes! In chorus.

Ms Saidi: What is she doing in picture number 1?

Mr Nkinga: Do you see the picture number 1 ? Can you see it? What is she doing? Answer in full sentence.

Colleague B: She is eating an apple ... no ... fruit.

Mr Nkinga: She is eating a fruit. Of course, it is an apple. Is she correct?

The whole group: Yes. In chorus.

This second vignette is qualitatively different from the first. Resources had been prepared as a stimulus to questioning and the teacher learners had to formulate their own responses rather than being told what to say. Although the overall interaction remained teacher-centred, in a small way emphasis was shifting from teacher to learners, for example in the use of questions to add to the chanting and repetition that was a common pedagogy. There was intention to seek individual responses rather than choral answers, a difficult shift given dominant pedagogical patterns. Sustainable capacity building then was both an aim of the project and an overarching framework to locate the specifics of the pedagogy of the teaching of English which was the substantive focus of the research.

\subsection{Grammar and the teaching of English}

The evidence from observations of the teacher's lessons, and the professional conversations that took place in the workshops, revealed that to a large extent the teaching of English was synonymous with formal grammar teaching. This reality is in itself significant as the particular focus and emphasis on grammar meant that other aspects of English learning and teaching were neglected as a consequence.

The most common pattern of English teaching initially observed in the research was teachers' explanation of metalinguistic terms such as 'preposition', and a focus on the 'rules' of English grammar. During teaching, the pupils usually contributed one-word answers in unison. The closed question, short answer interaction frequently included repetition by the whole class of a model answer given by teachers or repetition by the whole class of correct answers given by an individual pupil. These introductory whole class aspects of the lessons were followed by written exercises often involving the pupils copying sentences written on the blackboard into their exercise books. The English teacher, Ms Towo's standard seven lesson on active and passive verbs was typical of this kind of grammar-oriented lesson.

"The monkey eats a mango (active voice)" [written on the blackboard] 
Ms Towo: This is active voice. So, as usual, we take the last wordie to become the first wordie. This 'a mango' comes first. Is 'mango' singular or plural? Ugh? Pupils: Singular! In chorus.

Ms Towo: If it is singular, so how do you ... the auxiliary verb is, which one?

Pupils: Is. In chorus.

Ms Towo: Past participle of 'it' is what?

A few pupils: ... eaten! .

Ms Towo: Then, the past participle of the verb 'eat' is what?

Ms Towo and pupils: Eaten! In chorus.

Ms Towo: So, as usual, don't forget to write the word 'by' in front of 'the monkey'. Then this first wordie become the last wordie.

Ms Towo: Uhaona? (Do you get it?). Imeeleweka hapo? (Have you understood that?)

Pupils: Ndiyo, ndiyo! (Yes) loudly

Ms Towo then reads out a sentence written on the blackboard.

Ms Towo: 'A mango is eaten by the monkey'. This is passive voice. So, change the following sentences into passive voice ...

As can be seen from the Kiswahili transliteration, code switching was common. Our analysis of the data led us to regard code switching as a necessary means to ensure that the pupils maintained their understanding of the lesson, and the use of the English language that was being taught. More than a pedagogical requirement this reflected the pragmatic need to use all available languages to aid simple and more complex forms of understanding by the pupils. However, this pragmatic attention to the centrality of meaning as part of code switching had not, prior to the professional development activities, prompted the teachers to question the limited attention to meaning that was a result of their emphasis on metalinguistic terms.

The emphasis on formal grammar teaching resulted from the teachers' understanding of pedagogy, their knowledge of the English language, school custom and practice, and individual teachers' experience. The professional development workshops provided the teachers with the first opportunity in their careers to discuss their pedagogy in depth through viewing of videos of their lessons. Over the two years of the work it became evident that small incremental changes in practice were emerging which we attributed to a combination of the input from the research team and the school's commitment to helping their pupils develop their English language knowledge. The following extract of teaching from early in the project illustrates both traditional custom and practice in the first part of the lesson but also a small example of different teaching practice. The lesson was a standard six lesson on grammatical prepositions.

All pupils stood up to greet the teacher. Following an instruction from the teacher the pupils sat down. The teacher, Ms Mhina, picked up the chalk from a box and walked over to the blackboard. While she was 
writing the title, 'prepositions', pupils were watching her quietly. No textbooks or notebooks were seen on their desks. After she finished writing on the board she turned to the pupils.

Ms Mhina: Did you use it before?

Pupils: Yes/no! Different answers from different children.

Ms Mhina: Who is ... prepositions? Ugh? Prepositions? Repeated.

Some pupils raised hands to answer. The teacher pointed to a girl.

Pupil A: On

Ms Mhina: Very good. Another?

Pupil B: Under

Ms Mhina: Very good! Another?

Pupil C: Between.

The teacher continued asking questions and answers of this kind for another 10 minutes, then started drawing pictures on the blackboard.

Ms Mhina: Be quiet!

Ms Mhina: Look on the blackboard. The ball is ... the ball is ...?

Pupils: In

Ms Mhina: Is it in?

Pupils: Under

Ms Mhina: The ball is under the table.

Pupils: The ball is under the table. In chorus

Ms Mhina: Repeat!

Pupils: The ball is under the table.

Ms Mhina: Very good!

The beginning of this lesson revealed the typical teacher-pupil interaction that had been observed in most lessons. However, in the same lesson the teacher also employed a different approach to explain the grammatical concept of preposition using a context that focused on meaning.

Ms Mhina asked a girl and a boy to come up to the front of the class, and then she positioned the girl in front of the table.

Ms Mhina: Where is Victoria?

Pupil A: Victoria is in front of the table.

Ms Mhina: Yes, Victoria is in front of the table.

Pupils: Victoria is in front of the table. In chorus.

Ms Mhina positioned a boy behind the table.

Ms Mhina: Where is Rashed? Pupils were quiet. Where is Rashed, class?

Pupils: Rashed is behind the table. 
Ms Mhina: Yes, Rashed is behind the table. Class!

Pupils: Rashed is behind the table. In chorus.

Ms Mhian: Yes, class. Take out your exercise book.

The idea of using concrete examples to support teaching had been introduced in the professional development workshops, in part as a way to focus more on the meaning and communicative intent of phrases and sentences as opposed to decontextualised grammatical forms. However the teachers' development was not a simple linear shift from established practice towards different practice, nor did we expect this to be the case, as development depended on individual's prior experience and knowledge, and confidence to experiment with new teaching strategies.

In addition to the focus on meaning, the suggestions made in the workshops to use physical resources to enhance teaching assumed an importance beyond their physicality. The physical resources became mediators for pedagogical reflection and change. For example, as a result of a professional development workshop, a large format picture storybook was used by the standard five teacher for the first time in her career. Unlike the more limited change in practice in the example above of Ms Mhina, Ms Saidi's change in her observed practice was more dramatic. At the beginning of the lesson, she asked her pupils if they remembered the story of the book that she had read for them in the previous class. She spent about 17 minutes reading the story and trying to get pupils to engage in interaction with her.

The teacher was holding a large format copy of the book 'Peace at Last' by Jill Murphy.

Ms Saidi: Last week, we already read about this book, yeah? Are we?

Pupils: Yeah ...

Ms Saidi: Have you read about this book? All of you, yeah?

Pupils: Yes.

Ms Saidi: I want to ask the question about this book. Because we're already read this. So mshasoma kwenye kitabu? [So you have already read from the book]. Are we together? Tell me the story about this book. What have you learn about this book? Mlisoma nini mkaelewa kutoka hiki kitabu [What did you understand when you read from this book?]

Pupil A: Nimeelewa Mr Bear hapendi kelele [What she has said is My Bear does not like noise]

Ms Saidi: Mr Bear don't want noise. Is she right?

Pupils: Yes.

Ms Saidi: Yes, Mr Bear don't want noise. What else? Nini kingine mumesoma katika hiki kitabu [What else have you read in this book?]

Pupil B: Kulikuwa hakuna maelewano kati ya Mr Bear na family yake [There was argument between Mr Bear and his family]. Ms Saidi repeats what the pupil $B$ has said.

Ms Saidi: Is she right? 
Pupils: Yes!

Ms Saidi: Ehe nani mwingine ataniambia ameelewa nini kwenye kitabu? [Who else will tell me what they have understood from the book?] Kulikuwa kuna makundi mangapi? [How many groups were there?] The class must have previously read this book in groups. The whole class reply in chorus: 'nane' [eight].

Ms Saidi: Haya kundi la nane liko wapi? [Ok where is the $8^{\text {th }}$ group?] Milielewa nini kutoka hiki kitabu? [What did you understand from this book?]

Ms Saidi: Do you wanna read again?

Pupils: Yes. Loudly

The open question 'Tell me the story about this book' may seem inconsequential to some, but this represented a significant change from the interaction that was typical prior to the professional development. The question prompted recollection by the pupils of a complete story rather than attention to grammatical meta language. The teachers told us that this was the first time this kind of interaction around a book written in English had happened in the school. Code-switching was used effectively, and paradoxically although the greater use of Kiswahili reduced the total amount of use of English, the nature of questioning stimulated by the whole text resulted in engagement by the pupils with higher level concepts than had previously been observed. However, it is also probable that the code switching was a product of the limits of the teacher's knowledge of English resulting in the necessity to have some discussion in Kiswahili.

The change in practice only came about as a result of sufficient time to build capacity based on encouragement to change, experimentation in the classroom, feedback, reflection, and further sustained effort. In addition to books, some teachers' made use of posters or pictures for the first time. For instance, Ms Kiriaa a standard three teacher prepared a poster of a 'calendar of March' to teach the days of week. Through use of the poster she attempted to make pupils engage more in the lesson.

It was notable also that use of group-work or pair-work in classes was attempted or deployed in some classes to augment typical traditional pedagogical practice. In a standard seven class a kind of group-work was employed. Mr Nkinga divided the class into groups. He asked the pupils to sit in a group and then asked them to work through the questions about 'nationality'. Following the teacher's instruction, each group started to discuss the answers together. In similar vein, a new activity of pair-work was identified in Ms Towo's standard six class. For example, Ms Towo asked the whole class to pair up and then each pair was to present in front of the teacher and other peers. This pair-work mainly involved pupils memorising the dialogue and conversing with each other, which owed more to rote learning than communicative interaction.

In addition to seeking to understand the incremental changes in teachers' classroom practice we were also interested in the reasons for the patterns of teaching that we first observed prior to professional development input. In addition to teacher knowledge, 
teacher experience, and lack of opportunities for professional development another possibility was that national curriculum policy would influence teaching. The English Language Syllabus for Primary Schools, standard I - VII (The United Republic of Tanzania Ministry of Education and Culture, 2005) that prescribed teaching objectives does include a strong emphasis on the teaching of formal grammar in a way not sufficiently consistent with research evidence on effective teaching of English. However the government syllabus also included the requirement for contextualised English teaching:

... throughout the course you need to present new language in a meaningful context using pictures, realia, gestures or demonstration to make meaning clear to learners. Always involve your learners when teaching. Participatory, learnercentred and activity-based teaching will give better language results than nonparticipatory or teacher centred teaching (The United Republic of Tanzania Ministry of Education and Culture. 2005; p. 1).

Although this overarching requirement appeared to be somewhat rhetorical, in view of the heavy emphasis on formal grammar teaching in the syllabus, it is clear from the recommended activities that teachers were expected, for example, to use real objects in the classroom, and put pupils in pairs for role-play; etc. Our research revealed that the teachers only had limited knowledge of the English Language Syllabus hence their confidence and competence, linked with their limited knowledge and experience of the English language (within a wide range of knowledge between individual teachers), combined with custom and practice in the school, were the main reasons for the practice we first observed.

\subsection{Discussion and conclusions}

The research found that modest but significant changes to teachers' pedagogy, practice and understanding of the teaching of English, in the context of a low-income country in a highly deprived locality, could be achieved. One of the most important changes was in teacher confidence and capacity, for example in their increased understanding of the benefits of engaging learners in a greater range of interaction styles. Another important change was greater understanding of the importance of communicative intent and semantics in the teaching of English, and the beginning of a move from prescriptive views of language to descriptive views.

Improvements in physical resources linked to new pedagogical approaches, with the support of the whole school and expert guidance, had an important impact on teachers' practice not-with-standing the systemic challenges in the school and district that remained a major challenge. The central component of the research and professional development was to put the resourcefulness of teachers and school leaders at the centre, and with modest support by way of sharing expertise and provision of reading 
materials etc., seek to build pedagogical capacity in a multi-dimensional manner. The issue of resources and resourcefulness in educational development is a complex one that includes a focus on international benchmarking underpinned by a range of large scale international governmental and NGO activity with the aim to improve learning and teaching by improving teachers' capacity. It may be that such benchmarking and monitoring needs to take into account more seriously the resourcefulness of teachers from a capacity building perspective as part of the more tangible resourcing of schools by way of textbook provision etc.

Although our careful attention to changes in classroom practice showed significant gains for teacher practice there was also perhaps a more intangible intrinsic value to the professional development workshops. The profound impact of the opportunity for the head teacher and the teachers in the school to discuss pedagogy together cannot be underestimated. The teachers reported renewed confidence in their abilities, and they felt the workshops had contributed to their capacity building. The research team introduced the teachers to different approaches to teaching in the spirit of critical friendship. The use of video footage of lessons and the opportunity to reflect on practice was much welcomed. Gaining confidence and competence is not merely an end in itself. Rather, by investing in teacher learning through providing "help [for] others [you] "help yourself at the same time, constantly building capacity as those who were once helped become the helpers" (Hargreaves \& Fullan, 2012, p. 170). Building confidence and competence increases learning capacity thus building agency for change and improvement within schools as communities.

The main methodological limitation of the research was the focus on just one school. However, while we recognise the advantages of large-scale studies of language and literacy teaching in developing country contexts there remains a need for in-depth work. The multifaceted understanding of the subtle connections between, pedagogy, knowledge, resource and teacher development could not have been uncovered without the depth that is possible in a case study of the kind reported in this paper. Another limitation of the research was the many difficulties related to logistical organisation of timing of our visits in relation to uncertain school examination periods, national holidays and political events, and timing and location of professional development workshops. Systemic issues that are a constant issue for improving education were reflected in the logistical difficulties that we faced in spite of goodwill on all sides.

The place of English as a world language means that improvements in the teaching and learning of English are of interest to policy makers worldwide. The place of English does need to be understood in relation to the other languages that are part of the linguistic context of any country and region, however there is a pressing need, recognised by citizens and policy makers in many countries of the world, to improve the teaching and learning of English. Our research indicates that models of change are likely to be more effective if they are informed theoretically by understanding that whole school agency and participation are requisites of sustainable change. The combination of rigorous 
professional development activity, combined with research focused on that development (including in-depth reflection on classroom practice), appears to be an important element of sustainable professional development. But successful models of change need also to rigorously account for the substantive areas to be the focus for change. In the context of our research the teaching of English was just such an area. Because English was systematically connected to wider whole school change in our work, we argue, improvement was seen in greater teacher knowledge, a wider repertoire of practice, and growing understanding by the teachers of the ways in which teacher-pupil interaction is central to effective learning. Perhaps the more enduring legacy of this initiative is that the school continues to seek out further resources, thus sustaining and further developing its capability for sustained and sustaining improvement.

We are grateful to the Commonwealth Educational Trust (CET) for funding this work. The CET was not involved in any way during the writing of this paper.

\section{References}

Barrett, A. M., 1994. Why is English still the medium of education in Tanzanian secondary school? Language, Culture, and Curriculum, Vol. 7(1), 3-16.

Bartlett, L., \& Mogusu, E. (2013). Teachers' Understandings and Implementation of Learner-Centred Pedagogy. In F. Vavrus \& L. Bartlett (Eds.), Teaching in Tension: International Pedagogies, National Policies, and Teachers' Practices in Tanzania. Rotterdam: Sense Publishers.

Boon, M., 2007. The African Way The Power of Interactive Leadership (third edition). Cape Town: Zebra Press.

Brock-Utne, B., Desai, Z., Quorro, M., 2003. Language of Instruction in Tanzania and South Africa (LOITASA). E\&D Limited: Tanzania.

Brock-Utne, B., \& Holmarsdottir, H. B. 2004. Language policies and practices in Tanzania and South Africa: problems and challenges. International Journal of Educational Development, 24(1).

Darling-Hammond, L., and Lieberman, A., (Eds.). 2012. Teacher Education around the World. London: Routledge.

Day, C., (Ed.), 2012. International Handbook on Teacher and School Development London: Routledge.

Day, C., Sammons, P., Stobart, G., Kingston, A., Gu, Q., 2007. Teachers Matter Connecting Lives, Work and Effectiveness. New York: McGraw Hill and Open University Press.

Denzin, N., K., 1970. Sociological Methods a Source Book. Chicago: Aldine Publishing.

Easterly, W., 2006. The White Man's Burden: Why the West's efforts to aid the rest have done so much ill and so little good. Oxford: Oxford University Press.

Glaser, B., Strauss, A., 1967. The Discovery of Grounded Theory: strategies for qualitative research. New York: Aldine de Gruyter. 
Guskey, T. R., 2004. Foreword. In C. Day \& J. Sachs (Eds.), International Handbook on the Continuing Professional Development of Teachers (pp. xii-xiv). London: Routledge.

Hardman, F., 2010. Classroom discourse: towards a dialogic pedagogy. In D. Wyse, R. Andrews \& J. Hoffman (Eds.), The Routledge International Handbook of English, Language and Literacy Teaching. London: Routledge.

Hardman, F., Abd-Kadir, J., Tibuhinda, A., 2012. Reforming teacher education in Tanzania. International Journal of Educational Development, 32, 826-834.

Hargreaves, A., 2003. Teaching in the Knowledge Society. Buckingham: Open University Press.

Hargreaves, A., Fullan, M. 2012. Professional Capital Transforming Teaching in Every School. London: Routledge.

Harris, A., 2008. Distributed School Leadership Developing tomorrow's leaders. London: Routledge.

Kadeghe, M. (2010). In Defense of Continued use of English as the Language of Instruction in Secondary and Tertiary Education in Tanzania. In B. Brock-Utne, Z. Desai, A. Martha \& A. Pitman (Eds.), Language of Instruction in Tanzania and South Africa - Highlights from a Project. Rotterdam: Sense Publishers.

Lortie, D., 1975. Schoolteacher: A Sociological Study. Chicago: University of Chicago Press.

Leithwood, K., Mascall, B., Strauss, T., (Eds.), 2009. Distributed Leadership According to the Evidence. London: Routledge.

Lewin, K., \& Stuart, J. 2003. Insights into the Policy and Practice of Teacher Education in Low-income Countries: the Multi-Site Teacher Education Research Project. British Educational Research Journal, 29(5), 691-707.

Mercer, N., 2005. Sociocultural discourse analysis: analysing classroom talk as a social mode of thinking. Journal of Applied Linguistics, 1(2), 137-168.

Nye, J. S., 2008. The Power To Lead. Oxford \& New York: Oxford University Press.

O-Saki, K., Agu, A., 2002. A study of Classroom Interaction in Primary Schools in the United Republic of Tanzania. Prospects, 32(1), 103-116.

Ramadhani, S. (2007). Effect of tenure regularization program on building investment in Manzese ward in Dar es Salaam, Tanzania. MSc, Enschede, Netherlands.

Rubagumya, C., 1997. Language and Education in Africa: A Tanzanian Perspective. Clevedon: Multilingual Matters.

Sahlberg, P., 2011. Finnish Lessons What can the world learn from educational change in Finland? (with a foreword by Andy Hargreaves) New York: Teachers College Press.

Spillane, J., Diamond, J. B., (Eds.), 2007. Distributed Leadership in Practice. San Francisco: Jossey Bass.

Stiglitz, J., 2006. Making Globalization Work. London: Penguin.

Street, B., 2003. What's 'new' in New Literacy Studies? Critical approaches to literacy in theory and practice. Current Issues in Comparative Education, 5(2), 1-14. 
The United Republic of Tanzania Ministry of Education and Culture. 2005. English Language Syllabus for Primary Schools. Dar es Salaam: Tanzania Institute of Education.

United Nations, 2010. Millennium Development Goals Report 2010. Retrieved 25 July 2012 from: http://www.un.org/millennium goals/pdf/MDG\%20Report\%202010\%Eb\%20rl5\%20low\%20res\%20201000615\%20-pdf.

Uwezo, Sumara, S., 2010. Are Our Children Learning? Annual Learning Assessment Report: Tanzania 2010. Dar es Salaam: Uwezo.

Vygotsky, L., 1978. Mind in Society: The Development of Higher Psychological Processes. Cambridge, Mass.: Harvard University Press.

Vavrus, F., \& Bartlett, L. (Eds.). 2013. Teaching in Tension: International Pedagogies, National Policies, and Teachers' Practices in Tanzania. Rotterdam: Sense Publishers.

Wenger, E., 1998. Communities of Practice. Cambridge: Cambridge University Press. Yin, R., 2008. Case Study Research: Design and Methods (Applied Social Research Methods). London: SAGE.

Ziegler, J., Goswami, U. 2005. Reading Acquisition, Developmental Dyslexia and Skilled Reading Across Languages; A Psycholinguistic Grain Size Theory. Psychological Bulletin, 131(1), 3-29.

\footnotetext{
' However, these are not 'blackboards' in a conventional Western sense of the term. Rather, they are large rectangles of cement, a slab of concrete fixed to the 'front' wall of the classroom and painted black. Thus, depending on the quality of the mix of sand and cement and how recently or otherwise the surface had been painted, even the blackboard as a primary resource varied considerably in terms of quality and the degree of challenge to the teacher to render writing legible etc.
} 